\title{
An Ascl Boundary Library for the Studies of Genetic and Epigenetic Alterations in CpG Islands
}

\author{
Zunyan Dai, ${ }^{1,2}$ Dieter Weichenhan, ${ }^{4}$ Yue-Zhong Wu, ${ }^{1}$ Julia L Hall, ${ }^{1}$ \\ Laura J. Rush, ${ }^{1,3}$ Laura T. Smith, ${ }^{1}$ Aparna Raval, ${ }^{1}$ Li Yu, ${ }^{1}$ Daniela Kroll, ${ }^{5}$ \\ Joerg Muehlisch, ${ }^{5}$ Michael C. Frühwald, ${ }^{5}$ Pieter de Jong, ${ }^{6}$ Joe Catanese, ${ }^{6}$ \\ Ramana V. Davuluri, ${ }^{1}$ Dominic J. Smiraglia, ${ }^{1}$ and Christoph Plass ${ }^{1,7}$ \\ ${ }^{1}$ Division of Human Cancer Genetics, Department of Molecular Virology, Immunology and Medical Genetics, ${ }^{2}$ Department of \\ Pathology, ${ }^{3}$ Department of Veterinary Biosciences, and the Comprehensive Cancer Center, The Ohio State University, \\ Columbus, Ohio 43210, USA; ${ }^{4}$ Medizinische Universität zu Lübeck, Medizinische Klinik II, Ratzeburger Allee 16023538 \\ Lübeck, Germany; ${ }^{5}$ Klinik und Poliklinik für Kinderheilkunde, Pädiatrische Hämatologie/Onkologie, Universitätsklinikum \\ Münster, 48149 Münster, Germany; ${ }^{6}$ Children's Hospital, Oakland Research Institute, Oakland, California 94609, USA
}

\begin{abstract}
Knudson's two-hit hypothesis postulates that genetic alterations in both alleles are required for the inactivation of tumor-suppressor genes. Genetic alterations include small or large deletions and mutations. Over the past years, it has become clear that epigenetic alterations such as DNA methylation are additional mechanisms for gene silencing. Restriction Landmark Genomic Scanning (RLGS) is a two-dimensional gel electrophoresis that assesses the methylation status of thousands of CpG islands. RLGS has been applied successfully to scan cancer genomes for aberrant DNA methylation patterns. So far, the majority of this work was done using Notl as the restriction landmark site. Here, we describe the development of RLGS using Ascl as the restriction landmark site for genome-wide scans of cancer genomes. The availability of Ascl as a restriction landmark for RLGS allows for scanning almost twice as many CpG islands in the human genome compared with using Notl only. We describe the development of an Ascl-EcoRV boundary library that supports the cloning of novel methylated genes. Feasibility of this system is shown in three tumor types, medulloblastomas, lung cancers, and head and neck cancers. We report the cloning of 178 Ascl RLGS fragments via two methods by use of this library.
\end{abstract}

[Supplemental material is available online at http: / / www.genome.org.]

\begin{abstract}
Multiple genome scanning approaches have been developed in the past years to study genetic and epigenetic alterations in cancer (Gray and Collins 2000). The majority of those techniques target genetic alterations such as deletions, insertions, and copy number changes. Restriction Landmark Genomic Scanning (RLGS), a highly reproducible two-dimensional gel electrophoresis, allows scanning of genomes for DNA polymorphisms, DNA amplification, and DNA methylation (Hayashizaki et al. 1994a,b; Plass et al. 1996; Costello et al. 2000). The use of RLGS to study human cancers resulted in the identification of several novel genes that were amplified and overexpressed in malignant tissues (Costello et al. 1997; Frühwald et al. 2000). Furthermore, the use of methylation-sensitive restriction enzymes as landmark enzymes makes scanning of genomes for changes in the DNA methylation patterns possible (Dai et al. 2001; Frühwald et al. 2001b; Rush et al. 2001; Rush and Plass 2002). This is of particular interest in cancer genetics, because promoter methylation has been shown to be involved in the silencing of tumor suppressor genes (Jones and Laird 1999; Baylin et al. 2001; Costello and Plass 2001). The methylation-sensitive restriction landmark enzyme NotI has a GC-rich recognition sequence, which is preferentially located in $\mathrm{CpG}$ islands sequences, found mainly in promoter
\end{abstract}

${ }^{7}$ Corresponding author.

E-MAIL Plass-1@medctr.osu.edu; FAX (614) 688-4761.

Article and publication are at http://www.genome.org/cgi/doi/10.1101/ gr.197402. regions of genes (Costello et al. 2000). In normal tissue DNAs, these sites are unmethylated (Bird 1986). However, in tumors, methylation of a NotI site results in the absence of an RLGS fragment in the respective profile.

Although RLGS profiles can be generated from any highquality genomic DNA without prior sequence information, subsequent cloning of RLGS fragments is essential for future studies. Several PCR-based protocols have been developed allowing the identification of RLGS sequences (Ohsumi et al. 1995). More efficient, however, is a cloning strategy that uses an arrayed human library of NotI-EcoRV clones and RLGS mixing gel catalogs (Smiraglia et al. 1999). This protocol circumvents the need for PCR-based amplification, which could be problematic with GC-rich sequences. Successful use of this library system resulted in the identification of many methylation targets in several human tumors (Smiraglia and Plass 2002).

The use of the NotI-EcoRV boundary library as a cloning tool for RLGS is restricted to RLGS profiles that use the enzyme combination NotI and EcoRV as the first and second restriction enzymes. To increase the potential coverage of CpG islands, we developed reaction conditions for the use of AscI as the restriction landmark enzyme in RLGS. In addition, we prepared an AscI-EcoRV library and RLGS mixing gels that allow the efficient recovery of cloned RLGS fragments. We estimate that this novel resource, together with the NotIEcoRV library, will greatly increase the utility of RLGS and, in 
addition, provide access to up to 15,000 of the estimated $29,000 \mathrm{CpG}$ islands in the human genome (Venter et al. 2001).

\section{RESULTS AND DISCUSSION}

\section{Ascl and Notl Restriction Sites Predicted in the Human Genome}

The majority of RLGS gels generated to study DNA methylation profiles in human malignancies have used NotI as the restriction landmark enzyme. Many of these studies were supported by a NotI-EcoRV library (Smiraglia et al. 1999). To develop an additional landmark enzyme for the purpose of $\mathrm{CpG}$ island identification by RLGS, we analyzed the human genome sequence for the frequency and location of restriction sites for rare cutting, methylation-sensitive restriction endonucleases. AscI is a restriction enzyme that recognizes the target sequence GGCGCGCC and does not cut the methylated recognition sequence. Some characteristics of the loci cut by AscI obtained from the human genomic sequence (August 6, 2001 draft assembly of UCSC) are listed in Table 1 and compared with those cut by NotI. Surprisingly, the human genome possesses only half the number of AscI sites (4935) as compared with NotI sites (9628), although both recognition sequences are composed of four guanines and four cytosines each, and both contain 2 CG dinucleotides. Nevertheless, NotI and AscI are highly comparable in terms of the types of loci they assess. Of particular note is the fact that $86 \%$ and $83 \%$ of these sites, respectively, are found in CpG islands, whereas only $5 \%$ and $7 \%$ are found in repetitive elements not associated with $\mathrm{CpG}$ islands. This strong bias of representation of CpG islands over repetitive elements is a major strength of RLGS using these two enzymes. Furthermore, $86 \%$ and $83 \%$ of these CpG islands, respectively, are associated with known genes or ESTs. These data indicate that AscI is an excellent choice of landmark enzyme to complement RLGS studies performed using NotI. In addition, because NotI and AscI sites colocalize in only $3.7 \%$ of CpG islands, by using AscI as a second landmark enzyme, we are able to almost double the number of $\mathrm{CpG}$ islands whose methylation status can be analyzed.

\section{RLGS Profiles Using Ascl as the Landmark Enzyme Display up to 2000 Distinct CpG Islands}

We established the reaction conditions for the use of $A s c \mathrm{I}$ as a restriction landmark site (see Fig. 1 for an outline of the procedure). RLGS profiles with AscI show a lower fragment den- sity than NotI profiles (Fig. 2A), as expected from the genome sequence survey that identified fewer AscI restriction sites in the human genome (Table 1). An AscI master profile was prepared using total genomic DNA from three donors to maximize coverage of polymorphic spots. The master profile was labeled with a coordinate system of spot numbering (a portion is shown in Fig. 2D) as was done for the NotI master profile described previously (Costello et al. 2000). The lower density of RLGS fragments in an AscI profile allows the scoring of more fragments in the higher molecular weight sections. These sections are difficult to score in the NotI profiles due to the high density of spots and are frequently excluded from the analysis. Thus, although the number of fragments on an AscI profile is less than on a NotI profile, a similar number of $\sim 2500$ fragments can be analyzed on both.

Because AscI is methylation sensitive, we compared methylation frequencies detected by NotI and AscI in the same samples to determine whether both recognition sequences are equal targets for aberrant methylation in human malignancies. Table 2 summarizes the data obtained for nine lung cancers, six medulloblastomas, and three head and neck cancers. The number of methylated sequences detected with both restriction enzymes is not statistically different $(P \leqslant 0.05)$. These data indicate that although these enzymes assess different loci, they are similar in their abilities to detect aberrant methylation in human malignancies.

\section{Establishment and Initial Characterization of an Ascl-EcoRV Library}

The initial step in the construction of the AscI-EcoRV boundary library was the purification of $A s c \mathrm{I}-E c o \mathrm{RV}$ fragments from total genomic DNA using the BssHII/AscI restriction trapper. This procedure results in the enrichment of AscI-EcoRV fragments and eliminates $E c o$ RV-EcoRV fragments (see Methods for details). The quality of the purified AscI-EcoRV fragments was tested by using an aliquot of these fragments for RLGS separation. A portion of the purified AscI-EcoRV fragments was labeled and subjected to two-dimensional separation in the RLGS system. The resulting RLGS profile showed the same set of fragments as the original profile without prior purification (Fig. 2A,B), indicating that the purification did not result in loss or gain of certain fragments. The remaining purified material was used for cloning into pBluescript KS-AscI. The AscI-EcoRV library (A-RV-1) consists of 19,200 clones picked into fifty 384 well plates. The average insert size was $2.48 \mathrm{~kb}$ $(n=75)$ ranging from 0.3 to $10 \mathrm{~kb}$. Accordingly, the library has an expected bias toward smaller fragments, reflecting the

Table 1. Characteristics of Notl and Ascl Restriction Sites

\begin{tabular}{lcc}
\hline & Notl & Ascl \\
\hline Total number of restriction sites in the human genome ${ }^{a}$ & 9628 & 4935 \\
Number of restriction sites in CpG islands & $8239(86 \%)$ & $4071(83 \%)$ \\
Number of restriction sites in repetitive elements, not CpG islands & $520(5 \%)$ & $332(7 \%)$ \\
Frequency of restriction sites near 5' end of a known gene & $3357(34.9 \%)$ & $1612(32.7 \%)$ \\
Frequency of restriction sites near 3' end of a known gene & $1328(13.8 \%)$ & $725(15 \%)$ \\
Frequency of restriction sites inside a gene & $1392(14.5 \%)$ & $738(15 \%)$ \\
Frequency of restriction sites falling near ESTs & $2.221(23.1 \%)$ & $1001(20.3 \%)$ \\
Frequency of CpG islands with both Notl and Ascl sites & & $1100(3.7 \%)$ \\
\hline
\end{tabular}

aAugust 6, 2001 draft assembly of UCSC. 


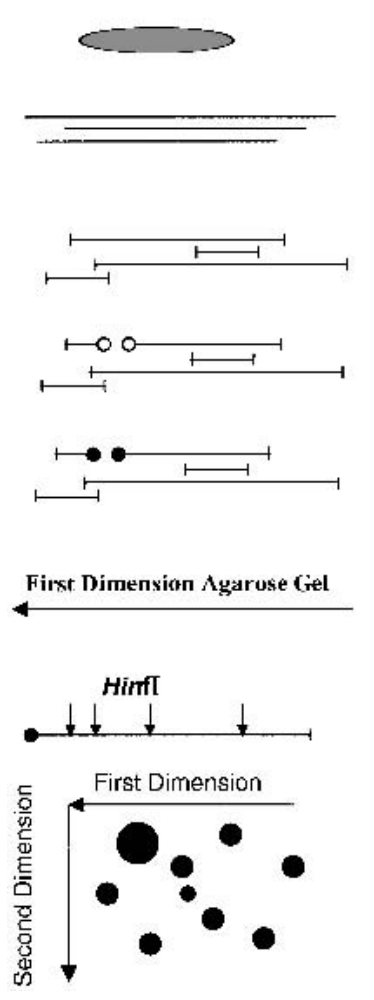

1. Isolation of high molecular weight genomic DNA from fresh or fresh frozen tissue.

II. Blocking of sheared DNA ends with $\alpha S$ dGTP, $\alpha S-d C T P$, ddATP, ddTTP, and DNA polymerase I to prevent non-specific labeling.

IIi. ECORV restriction digest.

IV. Ascl restriction landmark digest. AscI cuts only unmethylated restriction sites but not methylated.

V. Radioactive labeling of $A S C I$ restriction halfsites in a fill-in reaction using $\left[\left(x^{3}{ }^{3 / P}\right]\right.$ dGTP, $\left[\alpha{ }^{32} \mathrm{P}\right] \mathrm{dCTP}$ and Sequenase Ver. 2.0 .

VI. First dimension: High resolution $0.8 \%$ agarose gel electrophoresis to separate restriction fragments by molecular weight.

VII. In-gel digest of restriction fragments ușing HinfI.

VIII. Second dimension: Separation of restriction fragments in a $5 \%$ nondenaturing polyacrylamide gel.

IX. Gel drying and exposure to X-ray film.

\section{Establishment of Mixing Gels as a Cloning Tool for RLGS Fragments}

To generate a novel tool that will aid the cloning of RLGS fragments from profiles generated with AscI as the landmark enzyme and $E c o R V$ as the second restriction enzyme, we prepared RLGS mixing gels from plates 1 to 32 of the A-RV-1 library. In addition, the rows and columns from these 32 plates were individually pooled to produce 16-row pool (A-P) and 24 column pool (1-24) mixing gels. The procedure followed the strategy used previously for the generation of the NotI-EcoRV mixing gel catalog (Smiraglia et al. 1999). In RLGS mixing gels, fragments for which a corresponding clone is present in the pool of clones mixed with the genomic DNA will show enhancement. Determination of the plate, row, and column mixing gels in which the RLGS spot of interest is enhanced indicates the unique library address in which the corresponding RLGS fragment is cloned. An example of an RLGS mixing gel is shown in Figure 2C, with clones from a 384-well plate of the library. The average number of enhanced RLGS fragments per plate is 153 , as many of the clone insert sizes fall outside of the window of resolution of a standard RLGS profile. In the 32-plate mixing gels, there are 1468 unique RLGS fragments represented.

\section{Use of the Ascl-EcoRV Cloning Gel Catalog to Identify Hypermethylated Sequences in Various Cancers}

AscI is preferentially located within CpG islands and is methylation sensitive. Thus, AscI is useful as a restriction landmark enzyme in RLGS studies to identify methylation changes in two different samples. We used the methylation scanning properties of $A s c$ I to determine methylation changes in medulloblastoma (MB), lung cancer, and head and neck cancer (HNSCC) primary tumors relative to adjacent normal tissue, as well as cell lines representing all three tumor types and a leukemia cell line. RLGS fragment loss in tumor profiles and cell line profiles is the most prominent observation and is indicative of hypermethylation of those fragments. Less frequently, newly appearing RLGS spots are found on the tumor profiles that may represent hypomethylation. Unfortunately, however, such rare RLGS spots cannot be cloned using this library, because they are not present in the RLGS profiles of the DNAs used to create the library. Figure 3 shows an example of an RLGS fragment (RLGS fragment A2E54; in which A indicates the AscI profile and 2E54 indicates spot No. 54 in section $2 \mathrm{E}$ ) that is present in normal adjacent lung tissue DNA, but absent from the lung tumor and two lung cancer cell lines. The corresponding library clone was identified in the plate 4 , row I, and column 14 mixing gels. Clone 4I14 was isolated from the library and used in a single-clone mixing gel to confirm that the clone represents the intended RLGS spot (Fig. 3A). Insert DNA from this clone was used as a hybridization probe for Southern blot analysis to confirm methylation of the AscI site. Lung tumor and normal genomic DNA was digested with both EcoRV and AscI. Control DNA in lane 1 of Figure 3B was digested with EcoRV only. In the Southern analysis, the probe detects either a small (AscI-EcoRV) fragment or a larger (EcoRV-EcoRV) fragment. The presence of the large fragment indicates that the 


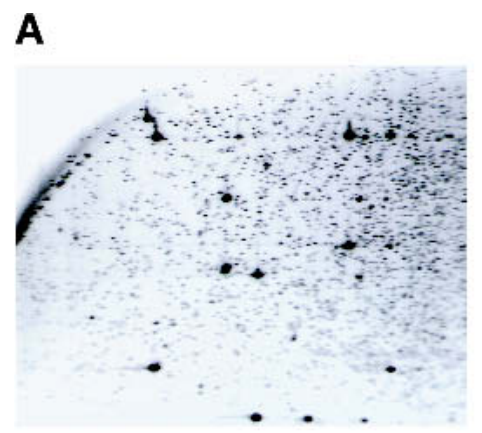

B
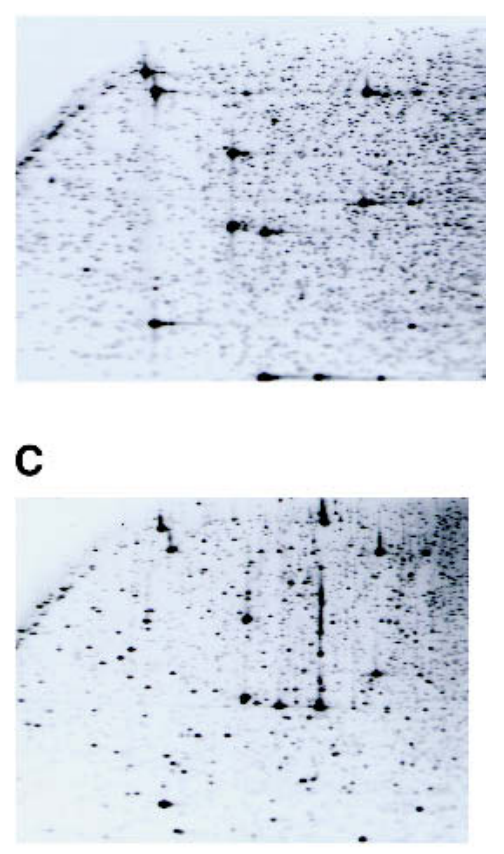

D

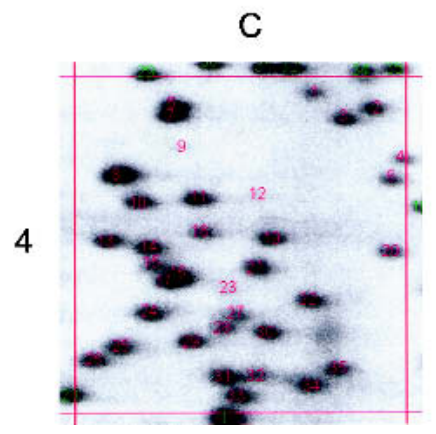

Figure 2 RLGS profiles using Ascl-EcoRV-Hinfl restriction enzyme combination. (A) RLGS profile of normal lung DNA. (B) RLGS profile using restriction trapper purified Ascl-EcoRV fragments derived from peripheral blood lymphocyte DNAs. (C) RLGS mixing gel generated with normal lung DNA as the genomic background and clones from plate 3 pool in the A-RV1 library. (D) Section 4C of the Ascl Master RLGS profile, showing the numbers assigned to each Ascl fragment.

AscI site was protected from restriction digestion by DNA methylation. The Southern data for patient 14 confirms the RLGS result. Similarly, 17 additional RLGS fragments have been cloned using this targeted approach and are shown in bold in Table 3 .

\section{Large-Scale Identification of RLGS Fragment Sequences}

A second nontargeted strategy to identify the sequences of RLGS fragments in AscI gels was also used. AscI-EcoRV clones derived from the A-RV-1 were sequenced from the AscI end. This sequence was used to determine the full-length AscIEcoRV and the AscI-HinfI restriction fragment sizes from the August 2001 freeze of the human genome. DNAs of clones with insert sizes of $0.5-5 \mathrm{~kb}$ and an AscI-Hinfl fragment $>100$ bp were pooled into groups of up to 15 plasmid DNAs and used for RLGS mixing gels. These mixing gels resulted in the enhancement of exactly the same number of RLGS fragments as the number of plasmid clones in the pool. Because the sequence, and thus the predicted mobility of these clones in RLGS gels was known, it was possible to unambiguously identify which clone and sequence corresponds with each RLGS fragment. By use of this strategy, it was possible to identify 160 additional RLGS fragments and their sequences. This data is summarized in Table 3, which is sorted by methylation status and chromosomal location. Of the total number (178) of AscI fragments cloned by the two methods described, we found 70 that were methylated in primary tumors and 119 methylated in cancer cell lines (Table 3; see supplemental data online for the complete list of cloned RLGS fragments).

\section{Conclusion}

We have developed a valuable resource for isolating and studying CpG-rich regulatory human sequences using AscI as a restriction landmark enzyme. AscI is as suitable as NotI to determine methylation patterns in human malignancies and nearly doubles the set of loci that can be studied. The AscI recognition sequence occurs less frequently in the genome than the NotI sequence, but its location is similarly biased toward $\mathrm{CpG}$ islands. The cloning gel catalogs now available for NotI-EcoRV and AscI-EcoRV allow for the targeted cloning of up to 3257 RLGS fragments [1789 from NotI (Smiraglia et al. 1999), 1468 from $A s c I],>90 \%$ of which are expected to represent CpG islands (Smiraglia and Plass 2002). In addition, we have developed a nontargeted, but higher throughput strategy for using these libraries to clone RLGS fragments.

By applying these cloning strategies, we have created a novel resource, which when used in conjunction with RLGS analysis of tumor profiles, allows for the identification of large numbers of methylation targets. Even in this limited study of 18 analyzed primary tumor profiles, we have already identified 70 targets of hypermethylation in cancer. Three of the genes that were identified, HOXA11, NELL1, and ALX3 have been identified previously by others as methylation targets in lung adenocarcinomas (Shiraishi et al. 2002a,b) or neuroblastomas (Wimmer et al. 2002), respectively. As we increase the number of tumor profiles analyzed and go through multiple iterations of the cloning strategies describe in this article, we will significantly increase the number of targets of hypermethylation that we can identify. This is a requisite step to begin to understand the mechanisms and consequences of such hypermethylation.

Together, there are a little over 15,000 NotI and AscI restriction sites in the human genome. Considering the total number of 29,000 CpG islands in the human genome (Venter et al. 2001), these libraries provide access to nearly half of the 
Table 2. Methylation Frequencies in Various Tumor Samples Determined by Either Notl or Ascl as a Restriction Enzyme

\begin{tabular}{|c|c|c|c|c|c|c|c|}
\hline \multirow[b]{2}{*}{ Tumor type } & \multicolumn{3}{|c|}{ NotI RLGS gels } & \multicolumn{3}{|c|}{ Ascl RLGS gels } & \multirow[b]{2}{*}{$\begin{array}{l}\text { Z-test statistic } \\
\text { for proportions }\end{array}$} \\
\hline & $\begin{array}{c}\text { No. of } \\
\text { methylated } \\
\text { CpG islands }\end{array}$ & $\begin{array}{l}\text { No. of RLGS } \\
\text { fragments } \\
\text { analyzed }\end{array}$ & $\begin{array}{c}\text { Methylation } \\
\text { frequency } \\
\text { in NotI gels }\end{array}$ & $\begin{array}{c}\text { No. of } \\
\text { methylated } \\
\text { CpG islands }\end{array}$ & $\begin{array}{l}\text { No. of RLGS } \\
\text { fragments } \\
\text { analyzed }\end{array}$ & $\begin{array}{l}\text { Methylation } \\
\text { frequency } \\
\text { in Ascl gels }\end{array}$ & \\
\hline Lung & 63 & 1184 & $5.3 \%$ & 78 & 1614 & $4.8 \%$ & 0.5833 \\
\hline Lung & 59 & 1184 & $5.0 \%$ & 62 & 1614 & $3.8 \%$ & 1.4669 \\
\hline Lung & 28 & 1184 & $2.4 \%$ & 49 & 1690 & $2.9 \%$ & -0.8735 \\
\hline Lung & 8 & 1184 & $0.7 \%$ & 8 & 1008 & $0.8 \%$ & -0.3234 \\
\hline Lung & 7 & 1184 & $0.6 \%$ & 13 & 1205 & $1.0 \%$ & -1.3079 \\
\hline Lung & 5 & 1184 & $0.3 \%$ & 18 & 1734 & $1.0 \%$ & -1.8470 \\
\hline Lung & 3 & 1184 & $0.3 \%$ & 7 & 1734 & $0.4 \%$ & -0.6822 \\
\hline Lung & 1 & 1184 & $0.1 \%$ & 3 & 1380 & $0.2 \%$ & -0.8503 \\
\hline Lung & 0 & 1184 & $0.0 \%$ & 5 & 1614 & $0.3 \%$ & -1.9169 \\
\hline$M B$ & 53 & 1702 & $3.1 \%$ & 20 & 923 & $2.1 \%$ & 1.4091 \\
\hline $\mathrm{MB}$ & 32 & 1768 & $1.8 \%$ & 22 & 1246 & $1.8 \%$ & 0.0903 \\
\hline$M B$ & 31 & 1825 & $1.7 \%$ & 21 & 1093 & $1.9 \%$ & -0.4401 \\
\hline$M B$ & 32 & 2016 & $1.6 \%$ & 19 & 1172 & $1.6 \%$ & -0.0735 \\
\hline MB & 15 & 1741 & $0.9 \%$ & 19 & 1327 & $1.4 \%$ & -1.4947 \\
\hline MB & 14 & 2018 & $0.7 \%$ & 9 & 1421 & $0.6 \%$ & 0.2140 \\
\hline HNSCC & 13 & 1703 & $0.8 \%$ & 14 & 1739 & $0.8 \%$ & -0.1387 \\
\hline HNSCC & 3 & 1839 & $0.2 \%$ & 6 & 1009 & $0.6 \%$ & -1.9625 \\
\hline HNSCC & 0 & 2126 & $0.0 \%$ & 1 & 1243 & $0.1 \%$ & -1.3080 \\
\hline
\end{tabular}

aHNSCC, head and neck squamous cell carcinomas; MB, medulloblastoma.

${ }^{b}$ Z-test static value for testing the significant difference in methylation frequencies in NotI and Ascl gels. All of the Z-static values are between -1.96 to +1.96 , which suggest that there is no significant $(p \leq 0.05)$ difference in methylation frequencies in NotI and Ascl gels.

CpG islands. Therefore, these libraries will prove to be excellent tools for the study of aberrant CpG island methylation when used in combination with various methylationscanning techniques such as RLGS and differential methylation hybridization (Frühwald and Plass 2002; Smiraglia and Plass 2002). Although standard RLGS running conditions only resolve a set of $\sim 2500 \mathrm{CpG}$ islands with a first dimension size of $5 \mathrm{~kb}-500 \mathrm{bp}$, these conditions can be altered to resolve a similar number of fragments with first dimension size ranging from 10 to $5 \mathrm{~kb}$ (Hughes et al. 1998). Thus, by modifying RLGS electrophoresis conditions and by utilizing other technologies that do not require electrophoresis, the full potential of these libraries may be achieved.

\section{METHODS}

\section{Tissue Samples and Cell Lines}

Frozen non-small cell lung tumors paired with normal adjacent tissues were collected through the Cooperative Human Tissue Network (CHTN). Nine paired samples (patient nos. 2, $3,5,7,10,11,13,14$, and 17) and clinical characteristics were described previously (Dai et al. 2001). Six medulloblastoma samples were described previously (Frühwald et al. 2001b). Three head and neck cancer tissues were collected at The Ohio State University through the CHTN. All sample collection was performed in accordance with NIH guidelines. Non-small cellline lung cancer lines A549 (from ATCC), H125, H1299, and H2086, head and neck cancer cell line SCC-9, leukemia cell lines HL-60, ML-1, and K-562, medulloblastoma cell lines Daoy, D425 MED, MHH-MED-1, and MHH-PNET-5, used in this study were described previously (Dai et al. 2001; Frühwald et al. 2001a; Rush et al. 2001, 2002; Smiraglia et al. 2001).

\section{Isolation of Plasmid and Genomic DNAs}

High molecular weight DNA for the RLGS procedure was isolated according to our previously published protocol (Smiraglia et al. 1999). Plasmid DNA was isolated using QIAprep
Spin Miniprep kit (QIAGEN) and the manufacturer's recommended protocols.

\section{RLGS}

RLGS was performed according to published protocols (Okazaki et al. 1994) with modifications for the use of $A s c$ I as the restriction landmark enzyme. Briefly, to prevent nonspecific labeling, the sheared ends of $\sim 7 \mu \mathrm{g}$ of genomic DNA were blocked in a $10-\mu \mathrm{L}$ reaction by the addition of nucleotide analogs $(\alpha \mathrm{S}$-dGTP, $\alpha$ S-dCTP, ddATP, ddTTP) using $2.5 \mathrm{U}$ of DNA polymerase I (Boehringer Mannheim) $\left(37^{\circ} \mathrm{C}, 20 \mathrm{~min}\right)$ followed by enzyme inactivation $\left(65^{\circ} \mathrm{C}, 30 \mathrm{~min}\right)$. The DNA was digested $\left(37^{\circ} \mathrm{C}, 2 \mathrm{~h}\right)$ with $20 \mathrm{U}$ of EcoRV (New England Biolabs), followed by $20 \mathrm{U}$ of $A s c \mathrm{I}$ (New England Biolabs) in NEB buffer $4\left(37^{\circ} \mathrm{C}, 2 \mathrm{~h}\right)$. The resulting restriction sites from AscI were labeled in a fill-in reaction using Sequenase Ver. 2.0 (USB) in the presence of $\left[\alpha-{ }^{32} \mathrm{P}\right] \mathrm{dGTP}(6000 \mathrm{Ci} / \mathrm{mmole}$, NEN Life Science Products) and $\left[\alpha{ }^{32} \mathrm{P}\right] \mathrm{dCTP}(3000 \mathrm{Ci} / \mathrm{mmole}$, NEN) for $30 \mathrm{~min}$ and stopped by adding buffer that included dCTP and dGTP. A portion of the reaction was electrophoresed through a $60-\mathrm{cm}$ long, $0.8 \%$ agarose tube gel (first dimension separation). The agarose gel was equilibrated in restriction buffer and the DNA was digested in the gel with 750 $\mathrm{U}$ of HinfI (New England Biolabs) at $37^{\circ} \mathrm{C}$ for $2 \mathrm{~h}$. The agarose gel was placed horizontally across the top of a nondenaturing $5 \%$ polyacrylamide gel, the two gels were connected with molten agarose, and the DNA was electrophoresed in the second dimension. The gels were dried and exposed to Kodak $\mathrm{X}$-OMAT AR film in the presence of one intensifying screen (Quanta 111, DuPont) for 2-10 d.

\section{Ascl Restriction Trapper Purification}

A mix of $500 \mu \mathrm{g}$ of total human genomic DNA from three donors was digested with $1500 \mathrm{U}$ of $A s c \mathrm{I}\left(37^{\circ} \mathrm{C}\right.$ for $\left.3 \mathrm{~h}\right)$, and subsequently with $500 \mathrm{U}$ of $E c o R V\left(37^{\circ} \mathrm{C}\right.$ overnight), extracted with phenol/chloroform/isoamyl alcohol (PCI), precipitated, and resuspended in $\mathrm{H}_{2} \mathrm{O}$ at a concentration of $2 \mathrm{mg} / \mathrm{mL}$. Aliquots of $100 \mu \mathrm{g}$ of restriction-digested DNA were ligated in 
Dai et al.

Table 3. Cloned Ascl Spots (See Supplemental Data Online for a Complete List of Cloned RGLS Fragments ${ }^{\mathrm{f}}$ )

\begin{tabular}{|c|c|c|c|c|c|c|c|}
\hline \multirow[b]{2}{*}{ RLGS spot } & \multirow[b]{2}{*}{ Chr. position ${ }^{a}$} & \multirow[b]{2}{*}{ Chr. band } & \multirow[b]{2}{*}{ CpG island ${ }^{b}$} & \multicolumn{2}{|c|}{ Methylation $^{c}$} & \multirow{2}{*}{$\begin{array}{l}\text { Gene or EST } \\
\text { homology }^{d}\end{array}$} & \multirow[b]{2}{*}{ Context $^{e}$} \\
\hline & & & & Primary & Cell lines & & \\
\hline A2D169 & chrNA_rdm:9890705-9892163 & $?$ & $\mathrm{Y}$ & $\mathrm{L}$ & L HN LU MB & DRD4/PTDSS2 & 5'end/Body \\
\hline A5E46 & chrX:17627774-17629763 & Xp22.13 & Y & $\mathrm{L}$ & L HN LU & - & - \\
\hline A4G14 & chr1:256787415-256787746 & $1 q 41$ & Y & $\mathrm{L}$ & L LU & - & - \\
\hline A2D08 & chr1:68251887-68253584 & $1 \mathrm{p} 32.1$ & $\mathrm{Y}$ & $\mathrm{L}$ & LU & JUN & Body \\
\hline A3F22 & chr1:108979505-108982150 & $1 \mathrm{p} 22.1$ & Y & $\mathrm{L}$ & $\mathrm{L}$ & - & - \\
\hline A3F38 & chr1:201154777-201155644 & $1 \mathrm{q} 24.2$ & $\mathrm{~N}$ & L HN MB & L LU & PMX1 & $5^{\prime}$ end \\
\hline A6E17 & chr1:133792275-133794522 & $1 \mathrm{p} 13.2$ & $Y$ & $\mathrm{~L}$ & L LU & - & - \\
\hline A3F30 & chr1:8129740-8132794 & $1 p 36.23$ & $\mathrm{~N}$ & $\mathrm{~L}$ & LU & EST & - \\
\hline A5E43 & chr1:127726863-127728875 & $1 \mathrm{p} 13.3$ & $\mathrm{Y}$ & L HN MB & L HN LU MB & $\mathrm{ALX} 3$ & 5 end \\
\hline A4E32 & chr1:22646645-22648732 & $1 \mathrm{p} 36.32$ & Y & $\mathrm{L}$ & L LU & - & - \\
\hline $\mathrm{A} 3 \mathrm{H} 43$ & chr1:2844351-2849754 & $1 \mathrm{p} 36.32$ & Y & $\mathrm{L}$ & L HN LU & - & - \\
\hline A2F45 & chr2:117320895-117322735 & $2 q 13$ & $\mathrm{~N}$ & L HN MB & L HN LU MB & EST & - \\
\hline A3E38 & chr2:179015764-179017423 & $2 q 31.1$ & $\mathrm{~N}$ & $\mathrm{~L}$ & $\mathrm{~L}$ & - & - \\
\hline A4D36 & chr2:138670622-138671469 & $2 q 21.2$ & $\mathrm{~N}$ & $\mathrm{~L}$ & L LU & - & - \\
\hline A4G44 & chr3:220718143-220722411 & $3 q 29$ & $Y$ & $\mathrm{~L}$ & HN LU & EST & - \\
\hline A5F32 & chr3:153653591-153655489 & $3 q 22.1$ & $\mathrm{~N}$ & L MB & L LU MB & - & - \\
\hline A5G07 & chr3:8664656-8665380 & $3 p 26.1$ & $\mathrm{Y}$ & L HN & L HN LU & GRM7 & $5^{\prime}$ end \\
\hline A5E28 & chr3:3902165-3903025 & $3 p 26.1$ & Y & $\mathrm{L}$ & L HN LU & - & - \\
\hline $\mathrm{A} 4 \mathrm{~B} 07$ & chr3:146695171-146695918 & $3 q 21.3$ & $\mathrm{Y}$ & $\bar{L}$ & HN LU & EST & - \\
\hline $\mathrm{A} 2 \mathrm{E} 14$ & chr4:5349208-5351766 & $4 \mathrm{p} 16.1$ & Y & L MB & L LU & HSA250839 & 5 ' end \\
\hline A2D23 & chr4:171849449-171850978 & $4 q 32.1$ & Y & L HN & L HN LU & GLRB & $5^{\prime}$ end \\
\hline A3E31 & chr4:181006489-181008945 & $4 q 32.3$ & $\mathrm{Y}$ & $\mathrm{L}$ & L LU & TLL1 & $5^{\prime}$ end \\
\hline A6E16 & chr5:49418697-49420952 & $5 p 11$ & Y & $\bar{L}$ & L LU & EST & - \\
\hline A4F02 & chr5:187652008-187654787 & $5 q 35.1$ & Y & $\mathrm{L}$ & & EST & - \\
\hline A6D30 & chr5:195984026-195984768 & $5 q 35.2$ & Y & $\mathrm{MB}$ & $\mathrm{MB}$ & B4GALT7 & $5^{\prime}$ end \\
\hline A3G33 & chr5:83731413-83731663 & $5 q 13.3$ & Y & $\mathrm{L}$ & L HN LU & MGC15435 & $3^{\prime}$ end \\
\hline A4C25 & chr6:103613999-103614941 & $6 q 15$ & Y & $\mathrm{L}$ & LU & $\mathrm{BACH} 2$ & $5^{\prime}$ end \\
\hline A3E39 & chr6:86748700-86751107 & $6 q 14.1$ & Y & L HN & L HN LU & EST & - \\
\hline
\end{tabular}

${ }^{a}$ BLAT search results based on http://genome.ucsc.edu/cgi-bin/hgBlat, Aug. 2001 Freeze.

bY indicates that the $A s c l$ site is within a $\mathrm{CpG}$ island, $\mathrm{N}$ indicates that it is not.

'Indicates methylation found in a primary tumor or cell line as indicated: (L) Lung carcinoma; (MB) medulloblastoma; (HN) head and neck squamous cell carcinoma; (LU) leukemia.

${ }^{d}$ Known genes found in the Refseq database or spliced ESTs.

' 5 ' end indicates that the $\mathrm{CpG}$ island includes the region immediately upstream of exon 1 and/or exon 1 . The 3 ' end indicates that the CpG island is found in $3^{\prime}$ most exon. Body indicates that the CpG island is found within the genomic structure of the gene excluding the $5^{\prime}-$ most and $3^{\prime}$-most known exons.

${ }^{f}$ Genes share same CpG island in their 5 ' end and are transcribed in opposite directions.

${ }^{9}$ Bold indicates the RLGS fragments that were cloned directly using the mixing gels.

$150-\mu \mathrm{L}$ volume to a $0.67 \%$ (w/v) DNA Trapper R-BssHII (Japan Synthetic Rubber Co.) in the presence of 10\% PEG 6000 using $1400 \mathrm{U}$ of T4 DNA ligase (New England Biolabs) at $18^{\circ} \mathrm{C}$ overnight. The DNA trapper-ligated DNA was digested twice with $100 \mathrm{U}$ of $E c o \mathrm{RV}$, centrifuged to remove nonligated EcoRV fragments, and then digested with $100 \mathrm{U}$ of AscI to release AscIEcoRV fragments. DNA fragments were PCI purified, precipitated in the presence of glycogen (Boehringer Mannheim), and dissolved in $13 \mu \mathrm{L}$ of TE buffer. A total of $11.8 \mu \mathrm{g}$ of purified DNA was recovered. To determine the quality and purity of the AscI-EcoRV fragments, $1 \mu \mathrm{g}$ was endlabeled with a fill-in reaction using Sequenase Ver. 2.0 in the presence of $\left[\alpha-{ }^{32} \mathrm{P}\right] \mathrm{dGTP}(6000 \mathrm{Ci} / \mathrm{mmole}$, DuPont $)$ and $\left[\alpha-{ }^{32} \mathrm{P}\right] \mathrm{dCTP}$ (3000 Ci/mmole, DuPont) and subjected to the twodimensional separation in the RLGS system. The resulting profile was compared with the RLGS profile prepared from total genomic DNA.

\section{Construction of Vector $\mathrm{KSII}^{+}$-Ascl}

To insert an AscI site (GGCGCGCC) into vector Bluescript $\mathrm{KSII}^{+}$(Stratagene), 50 pmole of each primer AscI-1 (CCACCGCGGTGGGCGCGCCT) and AscI-2 (CTAGAGGCGCGCCCACCGCGGTGGAGCT) (custom made by MWG Biotech) were annealed and subsequently ligated with $100 \mathrm{ng}$ of SacI-
$X b a$ I cut vector DNA. Appropriate insertion of the annealed primers would not disturb the ORF of the multiple cloning site and, hence, the vector's capability for blue/white selection on agar medium containing X-GAL. Escherichia coli DH10B (Life Technologies) were transformed with the ligation mixture and plated onto LB agar containing ampicillin, IPTG, and X-GAL. Blue colonies were tested for the presence of $\mathrm{KSII}^{+}$harboring an AscI site. One of such plasmids, designated $\mathrm{KSII}^{+}-\mathrm{AscI}$, was selected for subsequent library construction.

\section{Library Construction}

To facilitate reliable double digestions of vector $\mathrm{KSII}^{+}-$AscI with $A s c \mathrm{I}$ plus $E c o \mathrm{~V}$, we first shotgun cloned $A s c \mathrm{I}-E c o$ RV genomic fragments of mouse DNA into the vector. A clone with a $1.6-\mathrm{kb} A s c \mathrm{I}-E c o \mathrm{RV}$ insert was then used to prepare the vector for library construction. Two micrograms of the recombinant plasmid were $A s c \mathrm{I}-E c o$ RV digested and separated on a gel. The vector band was sliced out and run a second time on a gel to improve purity. The band was eluted and dissolved in $\mathrm{H}_{2} \mathrm{O}$ at a concentration of $10 \mathrm{ng} / \mu \mathrm{L}$. Self ligation of $10 \mathrm{ng}$ and subsequent electroporation of electrocompetent E. coli DH10B cells (Life Technologies; transformation efficiency $\sim 7-\times 10^{9}$ transformants/ $\mu \mathrm{g}$ pUC19) yielded in 45 clones. This figure 
A

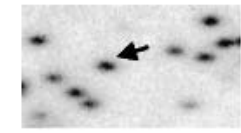

P14 normal

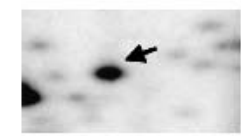

Plate 4

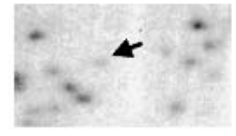

P14 tumor

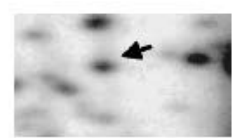

Row 1

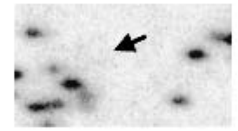

$\mathrm{H} 125$

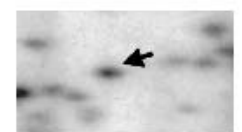

Column 14

B

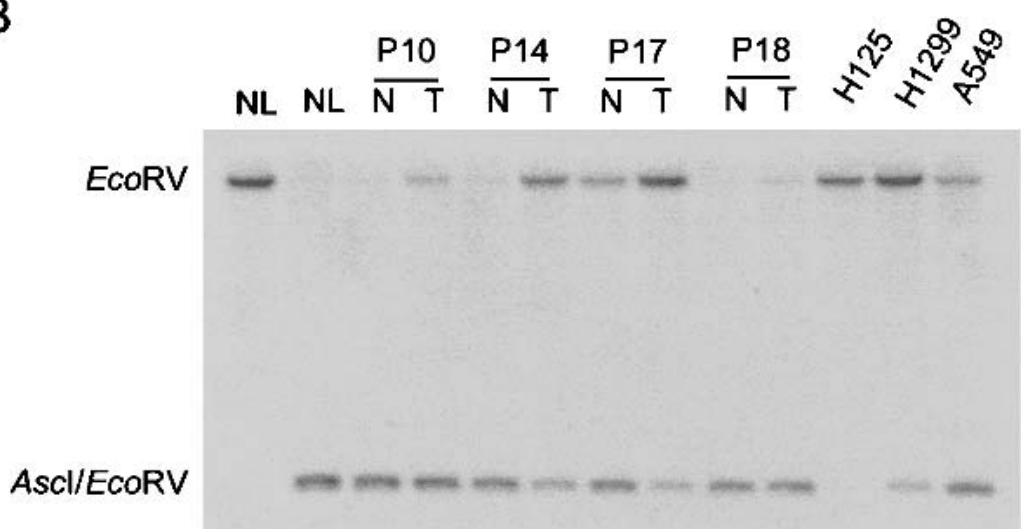

Figure 3 RLGS identifies DNA methylation in primary lung cancer. $(A)$ Sections from RLGS profiles including RLGS fragment A2E54 (arrow). Sections from normal and tumor profiles from patient 14 as well as two lung cancer cell lines (H1299 and H125) are shown. The corresponding Ascl-ECoRV clone was found in plate 4, row I, and column 14, and this clone was confirmed by use in a mixing gel. (B) DNA from Ascl clone 4114 corresponding to RLGS spot A2E54 was used for Southern analysis. DNAs from normal lung $(\mathrm{NL})$, lung tumors $(\mathrm{T})$, and adjacent normal tissue (N) from patients 10,14, 17, and 18, as well as from three lung cancer cell lines $\mathrm{H} 125, \mathrm{H} 1299$ and A549 were digested with AsCl and ECoRV. DNA in the first lane was digested only with EcoRV and shows the size of the EcoRV fragment. In the double digests, hybridization to the large EcoRV band is indicative of protection of the Ascl site digestion by methylation. The smaller band is indicative of cutting by AsCl.

indicated the expected nonrecombinants when $10 \mathrm{ng}$ of vector DNA were ligated with insert DNA at similar conditions. For library construction, two $10-\mu \mathrm{L}$ ligation mixtures, each containing $10 \mathrm{ng}$ of vector DNA, $3 \mu \mathrm{L}$ of human restriction trapper purified DNA and 0.5 U of T4 DNA ligase (Roche Diagnostics) were incubated at $16^{\circ} \mathrm{C}$ for $16 \mathrm{~h}$. After addition of $2.5 \mathrm{M} \mathrm{NH}_{4}$-acetate (final concentration) and $1 \mu \mathrm{L}$ of glycogen (stock: $20 \mathrm{mg} / \mathrm{mL}$; Roche Diagnostics) as carrier, the DNA was precipitated and redissolved in a total of $5 \mu \mathrm{L}$ of $0.5 \times \mathrm{TE}$. A total of $1 \mu \mathrm{L}$ of ligated DNA was used per transformation.

\section{Library Picking, Replication, and Preparation of High-Density Hybridization Filters}

Transformed cells were spread onto LB/Agar plates containing ampicillin $(100 \mu \mathrm{g} / \mathrm{mL})$, IPTG, and X-gal, and grown at $37^{\circ} \mathrm{C}$ for $18-20 \mathrm{~h}$. Clones were picked manually and arrayed into 384-well microtiter plates containing LB/ampicillin $(50 \mu \mathrm{g} /$ $\mathrm{mL}$ )/glycerol $(7.5 \%)$. The arrayed clones were incubated at $37^{\circ} \mathrm{C}$ for $18 \mathrm{~h}$, and then frozen at $-80^{\circ} \mathrm{C}$. Five additional copies of each plate were made using a 384-pin replicating tool (V \& P Scientific) for inocculation. The replicas were grown for $18 \mathrm{~h}$ at $37^{\circ} \mathrm{C}$ and then frozen at $-80^{\circ} \mathrm{C}$. Highdensity hybridization filters were prepared using a Q-Bot colony picker/high-density filter gridder. All clones from plate 1 to 48 were used to spot onto three $22.25 \times 22.25-\mathrm{cm}$ nylon

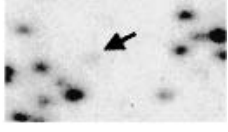

$\mathrm{H} 1299$

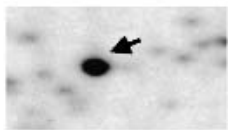

$4 \mid 14$ mixing gel membranes by use of protocols identical to the one used for BAC clones (Osoegawa et al. 2000).

\section{RLGS Mixing Gels With Clones From the Ascl-EcoRV Library (A-RV-1)}

Plates 1 to 32 from A-RV-1 were chosen for the RLGS mixing gels. Clone pool DNAs for each of the 32 plates, all 16 rows (A-P) and 24 columns (1-24) were prepared as described earlier (Smiraglia et al. 1999). Individual clones were grown in microtiter plates, overnight cultures were combined, and plasmid DNAs for each pool of clones were isolated using spin columns (QIAGEN). Genomic DNA from normal lung was labeled by a fill-in reaction using Sequenase Ver. 2.0 (USB) in the presence of $\left[\alpha^{-32} \mathrm{P}\right] \mathrm{dCTP}(6000 \mathrm{Ci} / \mathrm{mmole}$, NEN) and $\left[\alpha-{ }^{32} \mathrm{P}\right] \mathrm{dGTP}(3000 \mathrm{Ci} / \mathrm{mmole}$, NEN) for $30 \mathrm{~min}$. Pooled clone DNA was digested by EcoRV (Promega) and AscI (NEB) sequentially and labeled following the same procedure for standard RLGS. Ten picogram DNA per clone of labeled pooled clone DNA was mixed with the appropriate amount of labeled genomic DNA and loaded on the first dimension RLGS agarose gel followed by the standard RLGS procedure. The amount of labeled genomic DNA was optimized to obtain a 4-day exposure of the RLGS gel on $\mathrm{X}$-ray film.

\section{Sequencing and Database Analysis}

All sequence analyses were performed in the Core Facility of the Division of Human Cancer Genetics using an ABI PRISM 377 DNA sequencer. For CG-rich sequences high-annealing temperatures were employed using an ABI PRISM BigDye Terminator Cycle Sequencing kit. AscI-EcoRV clones were sequenced with M13 forward primer. DNA sequence files were analyzed using DNAstar and Chromas software. For homology searches, sequences were submitted to the publicly available databases.

\section{Bioinformatics}

The standard two-sided Z-test was used to compare the methylation frequencies in NotI and AscI test.

We downloaded the assembled sequences (August 6, 2001 draft assembly of UCSC) of the 24 chromosomes from the UCSC Human Genome Project working draft (http:// genome.ucsc.edu). We scanned each of the chromosomes for NotI (GCGGCCGC) and AscI (GGCGCGCC) sites, and retrieved the sequences that contain these sites. Each sequence is of a 1008-bp length ( -500 to +500 of the site). We used a sliding window $201 \mathrm{bp}$ in length, and counted the percentage of CpG dinucleotides (CpG score) and GC\% for each window. The sequence is considered a CpG island if there exists a sliding window with $\mathrm{CpG}$ score $\geqslant 60 \%$ and $\mathrm{GC} \% \geqslant 50$. We retrieved all of the 30,095 CpG islands mapped in the human genome and counted the number of $\mathrm{CpG}$ islands that have NotI and AscI sites. To determine whether these sites fall in a gene region or not, we used the public human genome annotations available at UCSC genome server. We counted the number of sites that fall in and around (within the $5-\mathrm{kb}$ region of the annotated gene ends) known genes and ESTs. 


\section{ACKNOWLEDGMENTS}

We thank Barbara Swiatkiewcz for her help with the clone spotting. The authors thank Drs. Hayashizaki and Okazaki for the generous gift of the restriction trapper. This work was supported in part by grants P30 CA16058, RO1 CA93548, and R01 DE13123 (CP). L.J.R. was supported by a T32 training grant CA09338 (PI, Michael Caligiuri) and grant CA089317 from NCI. M.F., D.K., and J.M. were supported by the Deutsche Krebshilfe (10-1699-Fr 1), the Deutsche Forschungsgemeinschaft (FR1516/1-1). C.P. is a Leukemia and Lymphoma Society Scholar.

The publication costs of this article were defrayed in part by payment of page charges. This article must therefore be hereby marked "advertisement" in accordance with 18 USC section 1734 solely to indicate this fact.

\section{REFERENCES}

Baylin, S.B., Esteller, M., Rountree, M.R., Bachman, K.E., Schuebel, K., and Herman, J.G. 2001. Aberrant patterns of DNA methylation, chromatin formation and gene expression in cancer. Hum. Mol. Genet. 10: 687-692.

Bird, A.P. 1986. CpG-rich islands and the function of DNA methylation. Nature 321: 209-213.

Costello, J.F. and Plass, C. 2001. Methylation matters. J. Med. Genet. 38: $285-303$.

Costello, J.F., Fr̈hwald, M.C., Smiraglia, D.J., Rush, L.J., Robertson, G.P., Gao, X., Wright, F.A., Feramisco, J.D., Peltomaki, P., Lang, J.C., et al. 2000. Aberrant CpG-island methylation has non-random and tumour-type-specific patterns. Nat. Genet. 24: $132-138$.

Costello, J.F., Plass, C., Arap, W., Chapman, V.M., Held, W.A., Berger, M.S., Su Huang, H.J., and Cavenee, W.K.1997. Cyclin-dependent kinase 6 (CDK6) amplification in human gliomas identified using two-dimensional separation of genomic DNA. Cancer Res. 57: 1250-1254.

Dai, Z., Lakshmanan, R.R., Zhu, W.G., Smiraglia, D.J., Rush, L.J., Frühwald, M.C., Brena, R.M., Li, B., Wright, F.A., Ross, P., et al. 2001. Global methylation profiling of lung cancer identifies novel methylated genes. Neoplasia 3: 314-323.

Frühwald, M.C. and Plass, C. 2002. Global and gene-specific methylation patterns in cancer: Aspects of tumor biology and clinical potential. Mol. Genet. Metab. 75: 1-16.

Frühwald, M.C., O'Dorisio, M.S., Rush, L.J., Reiter, J.L., Smiraglia, D.J., Wenger, G., Costello, J.F., White, P.S., Krahe, R., Brodeur, G.M., et al. 2000. Gene amplification in PNETs/medulloblastomas: Mapping of a novel amplified gene within the MYCN amplicon. J. Med. Genet. 37: 501-509.

Frühwald, M.C., O'Dorisio, M.S., Dai, Z., Rush, L.J., Krahe, R., Smiraglia, D.J., Pietsch, T., Elsea, S.H., and Plass, C. 2001a. Aberrant hypermethylation of the major breakpoint cluster region in 17 p11.2 in medulloblastomas but not supratentorial PNETs. Genes Chromosomes Cancer 30: 38-47.

Frühwald, M.C., O'Dorisio, M.S., Dai, Z., Tanner, S.M., Balster, D.A., Gao, X., Wright, F.A., and Plass, C. 2001b. Aberrant promoter methylation of previously unidentified target genes is a common abnormality in medulloblastomas-implications for tumor biology and potential clinical utility. Oncogene 20: 5033-5042.

Gray, J.W. and Collins, C. 2000. Genome changes and gene expression in human solid tumors. Carcinogenesis 21: 443-452.

Hayashizaki, Y., Hirotsune, S., Okazaki, Y., Shibata, H., Akasako, A., Muramatsu, M., Kawai, J., Hirasawa, T., Watanabe, S., Shiroishi, T., et al. 1994a. A genetic linkage map of the mouse using restriction landmark genomic scanning (RLGS). Genetics 138: $1207-1238$.

Hayashizaki, Y., Shibata, H., Hirotsune, S., Sugino, H., Okazaki, Y., Sasaki, N., Hirose, K., Imoto, H., Okuizumi, H., Muramatsu, M., et al. 1994b. Identification of an imprinted U2af binding protein related sequence on mouse chromosome 11 using the RLGS method. Nat. Genet. 6: 33-40.

Hughes, S.J., Glover, T.W., Zhu, X.X., Kuick, R., Thoraval, D., Orringer, M.B., Beer, D.G., and Hanash, S. 1998. A novel amplicon at 8p22-23 results in overexpression of cathepsin B in esophageal adenocarcinoma. Proc. Natl. Acad. Sci. 95: $12410-12415$.

Jones, P.A. and Laird, P.W. 1999. Cancer epigenetics comes of age. Nat. Genet. 21: 163-167.

Ohsumi, T., Okazaki, Y., Hirotsune, S., Shibata, H., Muramatsu, M., Suzuki, H., Taga, C., Watanabe, S., and Hayashizaki, Y. 1995. A spot cloning method for restriction landmark genomic scanning. Electrophoresis 16: 203-209.

Okazaki, Y., Okuizumi, H., Sasaki, N., Ohsumi, T., Kuromitsu, J., Kataoka, H., Muramatsu, M., Iwadate, A., Hirota, N., Kitajima, M., et al. 1994. A genetic linkage map of the mouse using an expanded production system of restriction landmark genomic scanning (RLGS Ver.1.8). Biochem. Biophys. Res. Commun. 205: 1922-1929.

Osoegawa, K., Tateno, M., Woon, P.Y., Frengen, E., Mammoser, A.G., Catanese, J.J., Hayashizaki, Y., and de Jong, P.J. 2000. Bacterial artificial chromosome libraries for mouse sequencing and functional analysis. Genome Res. 10: 116-128.

Plass, C., Shibata, H., Kalcheva, I., Mullins, L., Kotelevtseva, N., Mullins, J., Kato, R., Sasaki, H., Hirotsune, S., Okazaki, Y., et al. 1996. Identification of Grf1 on mouse chromosome 9 as an imprinted gene by RLGS-M. Nat. Genet. 14: 106-109.

Rush, L.J. and Plass, C. 2002. Restriction landmark genomic scanning for DNA methylation in cancer: Past, present, and future applications. Analyt. Biochem. (In press).

Rush, L.J., Dai, Z., Smiraglia, D.J., Gao, X., Wright, F.A., Frühwald, M., Costello, J.F., Held, W.A., Yu, L., Krahe, R., et al. 2001. Novel methylation targets in de novo acute myeloid leukemia with prevalence of chromosome 11 loci. Blood 97: 3226-3233.

Rush, L.J., Heinonen, K., Mrozek, K., Wolf, B.J., Abdel-Rahman, M., Szymanska, J., Peltomaki, P., Kapadia, F., Bloomfield, C.D., Caligiuri, M.A., et al. 2002. Comprehensive cytogenetic and molecular genetic characterization of the TI-1 acute myeloid leukemia cell line reveals cross-contamination with K-562 cell line. Blood 99: 1874-1876.

Shiraishi, M., Sekiguchi, A., Oates, A.J., Terry, M.J., and Miyamoto, Y. 2002a. HOX gene clusters are hotspots of de novo methylation in CpG islands of human lung adenocarcinomas. Oncogene 21: 3659-3662.

Shiraishi, M., Sekiguchi, A., Terry, M.J., Oates, A.J., Miyamoto, Y., Chuu, Y.H., Munakata, M., and Sekiya, T. 2002b. A comprehensive catalog of CpG islands methylated in human lung adenocarcinomas for the identification of tumor suppressor genes. Oncogene 21: 3804-3813.

Smiraglia, D.J. and Plass, C. 2002. The study of aberrant methylation in cancer via restriction landmark genomic scanning. Oncogene 21: 5414-5426.

Smiraglia, D.J., Frühwald, M.C., Costello, J.F., McCormick, S.P., Dai, Z., Peltomaki, P., O'Dorisio, M.S., Cavenee, W.K., and Plass, C. 1999. A new tool for the rapid cloning of amplified and hypermethylated human DNA sequences from restriction landmark genome scanning gels. Genomics 58: 254-262.

Smiraglia, D.J., Rush, L.J., Frühwald, M.C., Dai, Z., Held, W.A., Costello, J.F., Lang, J.C., Eng, C., Li, B., Wright, F.A., et al., 2001. Excessive CpG island hypermethylation in cancer cell lines versus primary human malignancies. Hum. Mol. Genet. 10: $1413-1419$.

Venter, J.C., Adams, M.D., Myers, E.W., Li, P.W., Mural, R.J., Sutton, G.G., Smith, H.O., Yandell, M., Evans, C.A., Holt, R.A., et al. 2001. The sequence of the human genome. Science 5507: $1304-1351$

Wimmer, K., Zhu, X.X., Rouillard, J.M., Ambros, P.F., Lamb, B.J., Kuick, R., Eckart, M., Weinhausl, A., Fonatsch, C., and Hanash, S.M. 2002. Combined restriction landmark genomic scanning and virtual genome scans identify a novel human homeobox gene, ALX3, that is hypermethylated in neuroblastoma. Genes Chromosomes Cancer 33: 285-294.

\section{Web Site References}

http://genome.ucsc.edu; Web site offers free access to the human genomic sequence.

Received February 20, 2002; accepted in revised form July 25, 2002. 


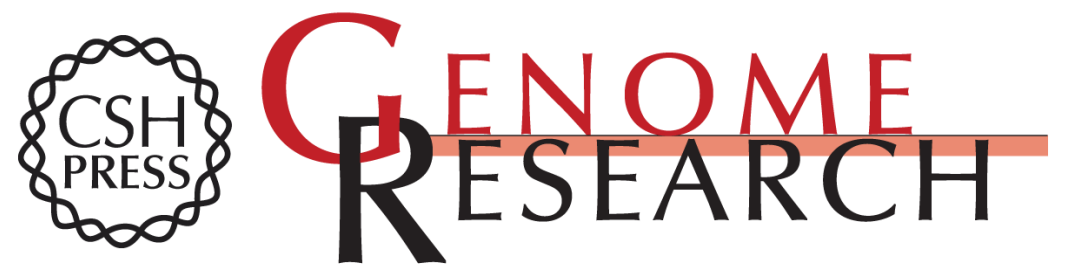

\section{An Ascl Boundary Library for the Studies of Genetic and Epigenetic Alterations in CpG Islands}

Zunyan Dai, Dieter Weichenhan, Yue-Zhong Wu, et al.

Genome Res. 2002 12: 1591-1598

Access the most recent version at doi:10.1101/gr.197402

Supplemental http://genome.cshlp.org/content/suppl/2002/10/20/12.10.1591.DC1

Material

References This article cites 28 articles, 8 of which can be accessed free at:

http://genome.cshlp.org/content/12/10/1591.full.html\#ref-list-1

\section{License}

Email Alerting Receive free email alerts when new articles cite this article - sign up in the box at the Service top right corner of the article or click here.

\section{Affordable, Accurate Sequencing.}

